\title{
Phloem Mobility and Stability of Sucrose Transporter Transcripts
}

\author{
Hongxia He ${ }^{1,2}$, Izabela Chincinska ${ }^{1}$, Aleksandra Hackel ${ }^{1}$, Bernhard Grimm ${ }^{1}$ and Christina Kühn ${ }^{1, *}$ \\ ${ }^{1}$ Institute of Biology, Plant Physiology, Humboldt University, Philippstrasse 13, Building 12, 10115 Berlin, Germany; \\ ${ }^{2}$ Institute of Genetics and Cytology, Northeast Normal University, No. 5268 Renmin Street, 130024, Changchun, \\ China
}

\begin{abstract}
Sucrose transporters are essential membrane proteins for the distribution of photoassimilates in higher plants. In Solanaceous species the proteins of all known sucrose transporters are co-localized in enucleate sieve elements and undergo permanent turnover. The mRNA of the sucrose transporter StSUT1 is localized in both, sieve elements and companion cells. Sucrose transporter mRNAs have been detected in the phloem sap of several species. Here, we analyzed the mobility of sucrose transporter transcripts in grafted plants and between host and parasitic plants. Phloem-mobility was found when a c-myc tagged SUT1-fusion construct without untranslated regions (UTRs) was expressed under the CaMV 35S promoter. We conclude that neither 3'- nor 5' -UTRs are essential for mRNA transport through plasmodesmata.

Cycloheximide, which inhibits translation, has also effects on SUT transcript stability. Whereas SUT1 transcripts are destabilized when translation is inhibited, SUT2 and SUT4 transcripts accumulate up to 4 fold under these conditions. Inhibitor studies revealed post-transcriptional regulation of SUT2 and SUT4 transcript accumulation. A model is proposed explaining the coordination of SUT expression in Solanaceae.
\end{abstract}

\section{INTRODUCTION}

Sucrose transport in Solanaceae was studied intensively in the past decades. Three different sucrose transporters have been identified from Solanum tuberosum and Lycopersicon esculentum [1-3]. Antisense inhibition of LeSUT1 and StSUT1 revealed an important role of SUT1 in phloem loading [4,5]. LeSUT2 from tomato was found to be expressed in pollen and pollen tubes and to be essential for pollen germination and pollen tube growth [6]. All three known transporters from potato, StSUT1, StSUT2 and StSUT4, have been co-localized in phloem sieve elements [7], but the phloem specific role of SUT2/SUT4 proteins still needs further elucidation. A dual function of the LeSUT2 protein is discussed [6]. Phylogenetic analysis shows redundancies among the major family of dicotyledonous SUT1 transporters with as much as 7 members in Arabidopsis thaliana, whereas only one single member of sucrose transporters can be found in SUT2 or SUT4 subfamilies per species [8] suggesting a function different from SUT1 for these proteins.

Whereas the SUT1 protein was detected immunocytochemically in the sieve elements of the phloem, the mRNA of the SUT1 transporter was localized electron microscopically in both, the sieve elements and the companion cells of the phloem [9]. Since the use of the companion cell-specific rolC promoter inhibited successfully the expression of the StSUT1 gene, it was concluded that the SUTI mRNA is transcribed in phloem companion cells and translocated via the branched plasmodesmata connecting companion cells and sieve elements [5]. Indeed, the StSUT1 mRNA molecules were preferentially associated to these branched plasmodes-

*Address correspondence to this author at the Institute of Biology, Plant Physiology, Humboldt University, Philippstrasse 13, Building 12, 10115 Berlin, Germany; Tel: +49 302093 6103; Fax: +49 302093 6337; E-mail: Christina.kuehn@biologie.hu-berlin.de mal structures [9]. The ability of the StSUT1 mRNA to move from one cell into another via plasmodesmata was confirmed by microinjection experiments with or without the RNAbinding phloem protein CmPP16 [10]. In many plant species, SUT1 mRNA was detected in the phloem sap collected by aphid stylectomy via RT-PCR, whereas amplification of other mRNAs i.e. from the potassium transporter HAK1 failed [11-13].

The phloem mobility of many phloem specific mRNAs and proteins has been analyzed in detail via interspecific graft experiments [12]. So far, nothing is known about the phloem mobility of sucrose transporter mRNAs. By intraspecific graft experiments using transgenic potato and tobacco plants we were able to show that indeed the mRNA of the sucrose transporters StSUT1 from potato and NtSUT1 from tobacco are phloem mobile between grafted plants and between host plants and the holoparasite Cuscuta reflexa.

mRNA molecules require protection against nucleolytic degradation during transport through plasmodesmata and during long distance transport in the phloem. So is known that the StSUT1 protein decreases within only $4 \mathrm{~h}$ of CHX treatment [9] and the accumulation of sucrose transporter mRNA follows a diurnal rhythm at least in Solanaceae and carrot plants $[9,14]$. This indicates an apparent short half life of sucrose transporter mRNA and protein.

We performed a detailed analysis of the transcript stability. Inhibitor studies revealed that expression of members of the SUT2 and SUT4 family undergo completely different regulation as described for sucrose transporters belonging to the SUT1 subfamily. Whereas SUT1 is mainly under transcriptional control, SUT2 and SUT4 transcript accumulation depends on a post-transcriptional mechanism as well. New aspects will help to elucidate the coordination of sucrose transporter expression. 


\section{METHODS}

Plant material. Transgenic plants were kindly provided by G. Leggewie [15] and A. Weise [16,17]. Cuscuta reflexa was kindly provided by Kirsten Krause, University of Kiel. Cuscuta reflexa was grown in potato and tobacco plants for at least two weeks before harvest. To avoid contamination, RNA samples from Cuscuta reflexa were taken in a $2 \mathrm{~cm}$ distance from haustoria between host and parasite.

Plant growth conditions and tissue culture. Potato plants in sterile culture were grown on 2MS-medium (MSmedium according to reference [18] with $2 \%$ sucrose) in tissue culture chambers at $24^{\circ} \mathrm{C}$, at $50 \%$ humidity and 1000 $\mu$ mol photons $\mathrm{m}^{-2} \mathrm{sec}^{-1}$ with a light/dark cycle of $16 \mathrm{~h} / 8 \mathrm{~h}$. Following transformation, leaf discs were put on $2 \mathrm{MS}$ with 1 $\mu \mathrm{g} / \mathrm{l}$ naphtyl acetic acid and $0.1 \mu \mathrm{g} / \mathrm{l}$ benzyl amino purine. For the selection of transformant tissue, 3MS with $2 \mu \mathrm{g} / \mathrm{l}$ zeatin and $35 \mu \mathrm{g} / \mathrm{l}$ kanamycin was used. The root induction of plantlets was performed on $2 \mathrm{MS}$ with $2 \mu \mathrm{g} / \mathrm{l}$ indol butyric acid and $50 \mu \mathrm{g} / \mathrm{l}$ kanamycin. After 2 weeks, plantlets were placed on $2 \mathrm{MS}$ containing $50 \mu \mathrm{g} / \mathrm{l}$ kanamycin.

Greenhouse. Transgenic plants were amplified in tissue culture and 60 plants were transferred to soil and grown in a cycle of $16 \mathrm{~h}$ light $\left(22^{\circ} \mathrm{C}\right)$ and $8 \mathrm{~h}$ darkness $\left(15^{\circ} \mathrm{C}\right)$ in $60 \%$ humidity. The mean photosynthetic photon flux density (PPFD; 400-700 nm) was about $150 \mu \mathrm{mol}$ photons $\mathrm{m}^{-2} \mathrm{sec}^{-1}$ and additional illumination was provided by high-pressure sodium lamps SON-T Green Power and metal halide lamps MASTER LPI-T Plus (Philips Belgium, Brussels).

Grafting. Plants had 5-6 leaves when grafted. The experiment was performed as described in reference $[19,20]$. RNA was isolated from stem section with 1,5 , and $10 \mathrm{~cm}$ distance from the graft union.

\section{RNA Quantification by Real-Time PCR}

RNA was isolated from different organs of greenhouse grown L.esculentum Moneymaker, S. tuberosum Désirée or $N$. tabacum SNN as described [21]. Reverse transcription was performed with the Qiagen Omniscript RT Kit according to the manual. Optimised conditions included using oligo(dT) primers for the initial reverse transcription reaction on approximately $2 \mu \mathrm{g}$ of total RNA after digestion with RNase-free DNase (Qiagen).

Aliquots of $0.5 \mu \mathrm{l}$ of the $20 \mu \mathrm{l}$ RT-reaction were used for the subsequent PCR reaction in the presence of SYBR Green with Hot Goldstar Polymerase (Eurogentec) in a Rotor Gene Cycler (LTF) using the Rotor Gene Software Version 4.6.94. The best products were obtained with the following program: denaturation at $95^{\circ} \mathrm{C}$ for $30 \mathrm{sec}$, annealing for $30 \mathrm{~seconds}$ at $61^{\circ} \mathrm{C}$ and elongation for $30 \mathrm{sec}$ at $72^{\circ} \mathrm{C}$, in a program of 40 cycles in $25 \mu \mathrm{l}$ reaction volume. Relative quantification of LeSUT1 and LeSUT2 transcript amounts was always calculated in relation to the respective ubiquitin3 transcript level and given in $\%$ of ubiquitin or in $\%$ of the water control. Primers were designed to obtain a 50-150 bp amplicon using Primer3 software (http://frodo.wi.mi. edu/cgibin/primer3/primer3_www.cgi).

Primer sequences: Ubiquitin fw: CAC CAA GCC AAA GAA GAT CA; Ubiquitin rev: TCA GCA TTA GGG CAC
TCC TT; LeSUT1 fw: TTC CAT AGC TGC TGG TGT TC; LeSUT1 rev: TAC CAG AAA TGG GTC CAC AA; LeSUT2 fw: CCT ACA GCG TCC CTT TCT CT; LeSUT2 rev: GGA TAC AAC CAT CTG AGG TAC AA, LeSUT4 fw: TCT CCG CTG ATA TTG GAT GG; LeSUT4 rev: GCA ACA TCG AGA AGC CAA AA; StSUT2 fw: GCA ATG CAT TCG GTT CTC AT; StSUT2 rev: CGG GTC CCC ATG ATA GAC TT; StSUT1 fw: CAA TTT GGT TGG GCT CTT CA; StSUT1 rev: AGT AGC CGA CAA CTG GCT GA. NtSUT1 fw: TTG GGG CTG TTG AAC TC; NtSUT1 rev: GCA AAC AGC CAA CAC GAA AT; GUS fw: CAT GTC GCG CAA GAC TGT AA; GUS rev: GTC CAG TTG CAA CCA CCT GT; TEF fw: TGG AAC TGT CCC TGT TGG TC; TEF rev: ACA TTG TCA CCA GGG AGT GC; SoSUT1-RT-fw: CCC CCT GAA GCT AAA ATT GG; c-myc-RT-rev: AGT TGA GGT CTT CTT CGG AGA TTA G.StSUT1 primers for semi-quantitative RT-PCR: StSUT1 fw: TTT AGG TAC CAT GGA GAA TGG TAC AAA AAG; StSUT1 rev: GAG AGA TAT CCC ATG GAA ACC GCC CAT GGC GAC.

Real time PCR data were corrected by calculation of the PCR efficiency individually using the LinReg PCR software.

\section{Feeding Experiments and Inhibitor Studies}

Plants were grown in the greenhouse with a 16-hrlight/8-hr-dark cycle, and leaves were harvested from 3month-old plants. Petioles of detached leaves were re-cut while submerged in water, $2.5 \mathrm{mM}$ EDTA was added to inhibit callose formation, and the cut petioles were transferred to inhibitor or phytohormone containing solutions where they were kept for the indicated period of time under greenhouse conditions. Phytohormones (2,4-D or BAP) were used in a final concentration of $5 \mu \mathrm{M}$. The inhibitors $\mathrm{CHX}$ or MG132 were used at a concentration of $10 \mu \mathrm{M}$, actinomycin was used at $2 \mu \mathrm{M}$ and the final cordycepin concentration was $50 \mu \mathrm{g} / \mathrm{ml}$. All experiments were repeated several times independently.

The transcript amount of each messenger RNA was determined before and after the experiment by real time PCR. The messenger decay rate during actinomycin D or cordycepin treatment was used to calculate the half life of sucrose transporter mRNAs (Table 1).

\section{RESULTS}

Phloem Mobility Between Host Plant and Parasite: Detection of StSUT1 and NtSUT1 Transcripts in Cuscuta reflexa

Cuscuta reflexa (dodder) is a holoparasite able to form haustoria to the host plants in order to collect photoassimilates (Fig. 1). Hyphae of the parasitic plant build up symplasmic connections to the phloem cells of the host plant allowing the transport of macromolecules as shown by GFP movement from transgenic tobacco plants into $C$. reflexa [22]. C. reflexa uses potato as well as tobacco plants as a host (Figs. 1B, C), whereas tomato plants are resistant against the parasite [23]. We used $C$. reflexa to analyze the movement of StSUT1 and NtSUT1 mRNA from host to parasite. Both, the full length StSUT1 transcript as well as the NtSUT1 mRNA were detectable via RT-PCR in $C$. reflexa RNA grown for 2 weeks on potato or tobacco host plants respectively (Figs. 1B, 1C). No RT-PCR amplicon was detectable when Cuscuta was grown on other host plants like 


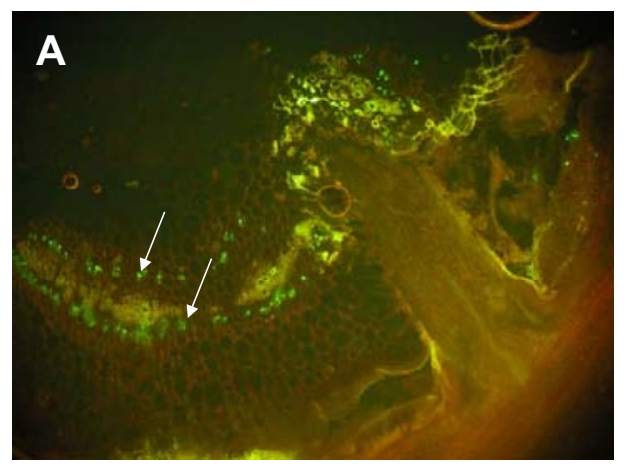

B
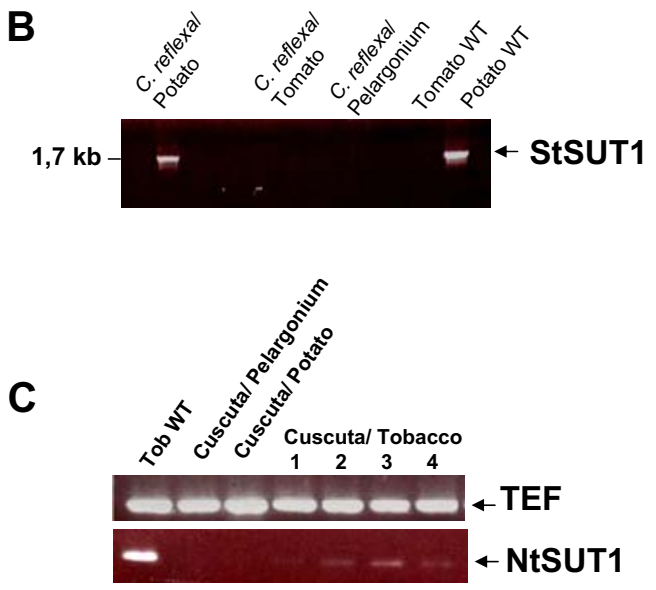

Fig. (1). A. Cross section of a Cuscuta reflexa haustorium on potato plants immunolabeled with RS21, a monoclonal antibody against a phloem-specific protein [40]. RS21 immunolabeling is detectable in the sieve elements of the bicollateral vascular bundle of the potato stem tissue and visualized by FITC-coupled secondary antibodies (arrows). B. RT-PCR with StSUT1-specific primers. Cuscuta RNA was isolated after 2 weeks of growth on the host plants and RT-PCR was performed using StSUT1 specific primers. Full length StSUT1 transcripts are only detectable in RNA from potato plants (right lane) and in Cuscuta if grown on potato plants (left lane). Specificity of the StSUT1-primers has been tested in tomato RNA and RNA from Cuscuta grown on Lycopersicon esculentum or Pelargonium. C. RT-PCR with RNA from Cuscuta reflexa grown for 2 weeks on tobacco or Pelargonium plants. Quality and amount of the reversely transcribed mRNA was tested using standard primers (translation elongation factor TEF). NtSUT1 specific primers were able to amplify NtSUT1 on RNA from tobacco plants and Cuscuta reflexa grown on tobacco plants, whereas no amplicon was detected with the negative control (Cuscuta grown on Pelargonium).

Pelargonium or in the no template control. To avoid contamination, Cuscuta samples for mRNA preparation were taken in at least two $\mathrm{cm}$ distance from haustoria between dodder and host plant. Thus, SUT1 mRNA movement was observed between host and parasite and requires passage through symplasmic connections between the parasitic and the host plants. In case of StSUT1, the full length transcript of $1.7 \mathrm{~kb}$ was detectable arguing for mRNA stabilization during long distance transport. The mRNA encoding the translation elongation factor TEF was used as a positive control for RNA and cDNA quality (Figs. 1B, 1C).

\section{SUT1 Transcripts are Phloem Mobile Between Grafted plants}

StSUT1 mRNA cell-to-cell movement through plasmodesmata was first shown by microinjection experiments with or without the RNA-binding protein CmPP16 from $\mathrm{Cu}$ curbita maxima [10]. In order to test whether StSUT1 mRNA mobility is also detectable in cells, where the short lived StSUT1 transcripts naturally occur, we performed intra- and interspecific grafts. Transgenic potato plants overexpressing a c-myc-tagged version of the SoSUT1 gene were used to answer the question whether untranslated regions of the SUT1 transcript are required for phloem mobility (Fig. 2A). The SoSUT1-c-myc gene does not contain untranslated regions of the mRNA since only the coding region of the cDNA was used for the construct [15]. Although neither the 5'UTR, nor the 3' UTR is included, phloem mobility of SoSUT1-c-myc mRNA was detectable by semi-quantitative RT-PCR (Fig. 2B). Thus, untranslated regions (UTRs) of SUT1 transcripts are not required for mRNA movement from one graft partner into the grafted WT potato plants.

\section{Phloem mobility of LeSUT1-GUS mRNA}

Phloem mobility of SUT1 transcripts was not only detected when the cDNA was expressed under a strong constitutive CaMV 35S promoter, but also when the tomato gene LeSUT1 was expressed under its own promoter in transgenic tobacco plants (Fig. 2C). We used a LeSUT1 promoter::LeSUT1-GUS fusion construct containing exon as well as intron sequences of LeSUT1 [17]. When the LeSUT1-GUS fusion protein was expressed under its own promoter, again phloem mobility of the corresponding mRNA could be observed in the grafted WT scion by RTPCR (Fig. 2C). Thus, even the larger mRNA is able to move in the phloem of grafted tobacco plants and phloem-mobility occurs not only if the gene is overexpressed under the constitutive $35 \mathrm{~S}$ promoter.

\section{In Silico Promoter Analysis of Genomic Sucrose Trans- porter Sequences}

The expression of sucrose transporters is under phytohormonal control. The expression of StSUT1 is inducible by auxin and by cytokinin as shown by Northern Blot Analysis [24] and StSUT4 is shown to be induced by ethylene and gibberellins [25]. The transcript level of all three known sucrose transporters from potato oscillates even under constant light conditions [25]. Promoter analysis by the Web Signal Scan Program (http: //www.dna.affrc.go.jp/sigscan/signal1 .pl) was performed with the genomic LeSUT1 and LeSUT2 sequences. The LeSUT1 promoter region contains consensus sequences involved in sugar repression, circadian expression, ethylene response, pollen specific expression, light regulation, guard cell specific expression, and induction by salicylic acid. Some of the genomic cis-regulatory elements are located in intron sequences such as the auxin responsive element (AuxRE), which represents the binding site of the auxin response factor ARF and which is located in the $3^{\text {rd }}$ intron of LeSUT1. A promoter sequence element for circadian evening genes is known, called evening element EE with the consensus AAAATATCT [26]. According to Harmer and Kay, an imperfect evening element of circadian genes is present in the LeSUT1 promoter [26]. 

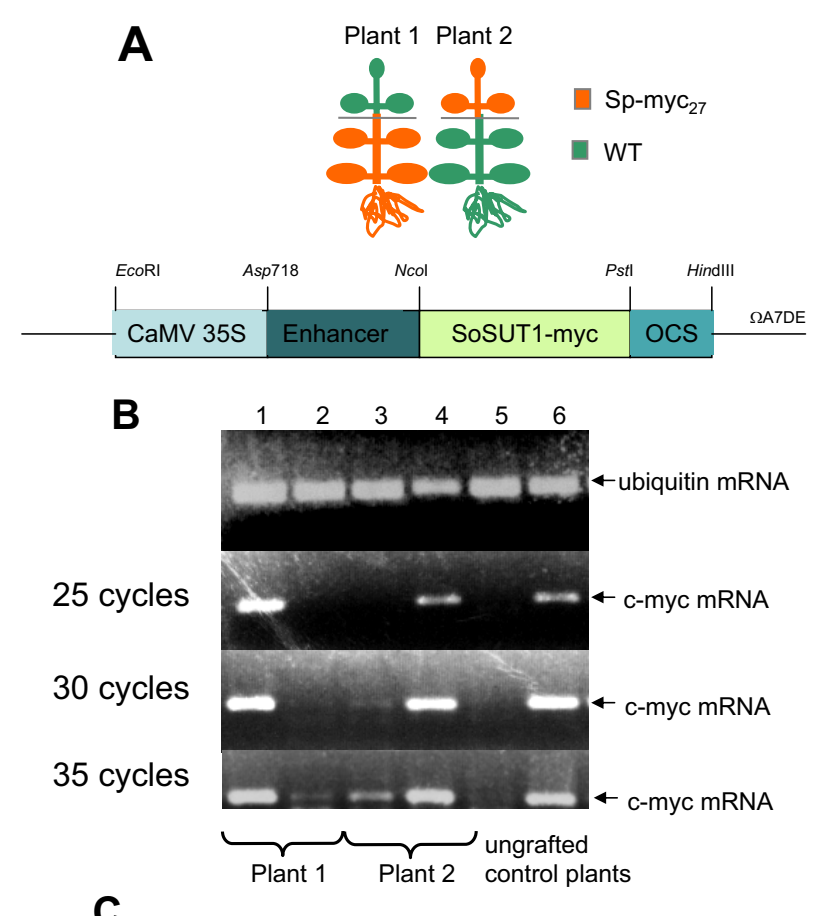

C

2,3 kb LeSUT1-promoter-GUS construct:

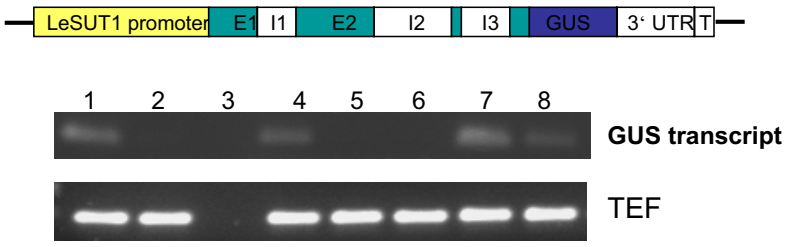

Fig. (2). A. Schematic representation of the intraspecific graft experiment (above) using transgenic potato plants overexpressing a tagged version of the SoSUT1 gene of Spinacia oleracea under the control of an enhanced CaMV35S promoter as indicated in the construct (below) used for transformation of Solanum tuberosum [15]. B. Semi-quantitative RT-PCR of the tagged SoSUT1 gene in grafted plants. Total RNA was assayed from the following tissues: Line 1 Sp-myc27 stock; line 2 Wild type scion; line 3 Wild type stock; line 4 Sp-myc27 scion; line 5 ungrafted Sp-myc27 potato; line 6 wild type potato. After 25 PCR cycles, the tagged SoSUT1myc gene is detectable only in the transgenic graft stock of plant 1 and in the transgenic graft scion of plant 2. After 30 PCR cycles, the SoSUT1-myc gene is also detectable in the WT graft partner. Ubiquitin was used as internal control. C. Phloem mobility of LeSUT1-GUS transcript expressed under the endogenous LeSUT1 promoter. Transgenic tobacco plants expressing a LeSUT1-GUS fusion construct under control of the $2,3 \mathrm{~kb}$ promoter fragment of LeSUT1 were grafted with WT tobacco plants [17]. LeSUT1-GUS transcripts are detectable in grafted wild type tobacco plants via RT-PCR. Line 1, transgenic LeSUT1-GUS plant line 38; line 2, tobacco wild type; line 3 no-template control; line 4, transgenic LeSUT1-GUS 38 stock; line 5, grafted wild type scion $1>10 \mathrm{~cm}$ from graft union; line 6 , grafted wild type scion $2>5 \mathrm{~cm}$ from graft union; line 7, grafted wild type scion $3>=1 \mathrm{~cm}$ from graft union; line 8 , grafted wild type scion $4<1 \mathrm{~cm}$ close to graft union. TEF (translation elongation factor) was used as internal control.

LeSUT2 is known to be expressed in pollen and to be essential in pollen development and pollen tube growth [6]. The orthologous gene from Arabidopsis, AtSUC3/AtSUT2 is wound inducible [27]. Analysis of the genomic LeSUT2 se- quence revealed cis-elements necessary for induction by $\mathrm{ABA}$ or SA, regulation by GA, ethylene, light, wounding, salt and water stress and for pollen specific expression. Additionally, two auxin response elements (AuxRE) are located in the SUT2 promoter region and in the $10^{\text {th }}$ intron arguing for a regulation via the auxin response factor (ARF).

\section{Half Life of Sucrose Transporter mRNAs}

The half life of sucrose transporter mRNAs was determined by help of actinomycin D as inhibitor of transcription and of cordycepin as inhibitor of polyadenylation. Most sense mRNA degradation follows first-order kinetics [28] and sucrose transporter transcript degradation can be fitted with first-order kinetics (R-squared greater than 0.9). The half life of LeSUT1 mRNA was $88.1 \pm 13 \mathrm{~min}$ and for StSUT1 mRNA $69.3 \pm 3$ min (Table 1, Fig. 3). This is in close proximity to what was found for the SUT1 mRNA from Beta vulgaris, BvSUT1: $108 \mathrm{~min}$. [29]. The half life of SUT2 and SUT4 mRNAs from potato and tomato show a longer half life of about $130 \mathrm{~min}$ as shown by transcription inhibition using actinomycin D or cordycepin (Table 1, Fig. 4). Since transcript accumulation of all three known sucrose transporters from potato follow a diurnal rhythm $[9,25]$, transcript amounts have been related to the corresponding water control after the indicated period of time.

The stability of the sucrose transporter protein StSUT1 is rapidly affected by $\mathrm{CHX}$ treatment shown by western blot analysis [9]. Sucrose transporter transcript accumulation was now investigated in the presence of cyloheximide and quantified by real time PCR analysis. The mRNA levels of both, StSUT1 from potato as well as LeSUT1 from tomato rapidly decreased within $4 \mathrm{~h}$ upon CHX application (Figs. 3A, 3B). Thus, in case of SUT1 not only the protein stability is affected by inhibition of translation, but also the transcript amounts.

In a very similar experiment analyzing the transcript accumulation of SUT2 and SUT4 transporters from potato and tomato in the presence of CHX, the inhibitor had the opposite effect on transcript amounts as shown for SUT1 mRNA. In contrast to SUT1 mRNAs, the levels of the SUT2 and SUT4 mRNAs from potato and tomato are stabilized in the presence of CHX: the mRNA amount increases strongly within the very short period of only $2 \mathrm{~h}$ upon CHX treatment (Fig. 4A, 4B). This is in agreement with the transcript amount of AtSUT2/AtSUC3 (accession no: At $2 \mathrm{~g} 02860$ ), the SUT2 ortholog in Arabidopsis, as analysed by microarray analysis available from the Arabidopsis co-response database (http://csbdb.mpimp-golm.mpg.de/csbdb/dbcor/ath/ath_txp. html). The level of AtSUT2 transcripts increases more than 4 fold after $3 \mathrm{~h}$ treatment with $10 \mu \mathrm{M}$ CHX. Thus inhibition of translation either increases transcriptional efficiency and/ or transcript stability of both SUT2 and SUT4 genes in tomato, potato and in case of SUT2 also in Arabidopsis.

\section{SUT Regulation at the Transcriptional and Post- Transcriptional Level}

Translational inhibition by CHX can affect the accumulation of sucrose transporter transcripts by two different processes: either reducing amounts of short-lived transcriptional regulators modify transcriptional activity or the stability of the already transcribed messenger RNAs is affected posttranscriptionally by RNA-binding factors. It is possible, that 
Table 1. Half life of different sucrose transporter transcripts as determined via real time PCR on mRNA isolated after feeding experiments with appropriate inhibitors. RNA quantification was performed in relation to the amount of ubiquitin transcripts as internal standard. Water treated plant material was taken as a reference. The standard deviation is given

\begin{tabular}{|c|c|c|c|}
\hline Gene & mRNA half life & Inhibitors & Reference \\
\hline \hline LeSUT1 & $88.1 \pm 13 \mathrm{~min}$ & cordycepin work & this work \\
\hline StSUT1 & $69.3 \pm 3 \mathrm{~min}$ & cordycepin; act D & {$[29]$} \\
\hline BvSUT1 & $108 \mathrm{~min}$ & cordycepin & this work \\
\hline LeSUT2 & $131.6 \mathrm{~min}$ & cordycepin & this work \\
\hline LeSUT4 & $131 \mathrm{~min}$ & cordycepin & this work \\
\hline StSUT4 & $131 \mathrm{~min}$ & act D & \\
\hline
\end{tabular}
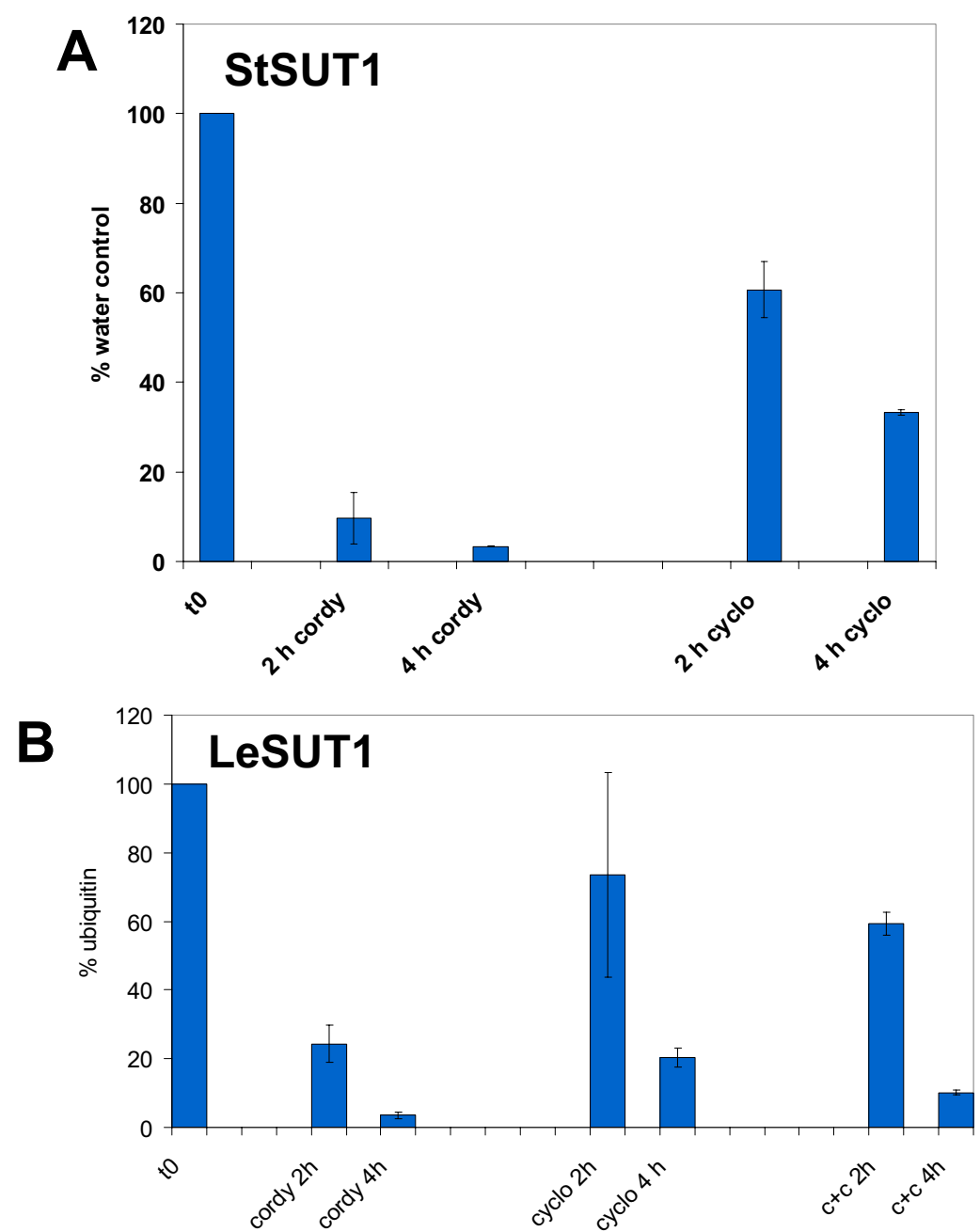

Fig. (3). Real time PCR analysis of sucrose transporter SUT1 mRNA stability in the presence of transcriptional and translational inhibitors A. Determination of StSUT1 half life by cordycepin (cordy) and CHX (cyclo). Half life of StSUT1 mRNA was calculated based on real time quantification and presented in table 1. B. Half life of LeSUT1 mRNA as determined by cordycepin treatment. $6 \mathrm{~h}$ after cordycepin supply no mRNA is detectable (not shown). StSUT1 and LeSUT1 mRNA half life decreases in the presence of the translational inhibitor CHX. Simultaneous incubation with cordycepin and CHX $(\mathrm{c}+\mathrm{c})$ does not lead to significant prolongation of LeSUT1 mRNA half life. Quantification of transcripts is relative to the amount of ubiquitin transcripts. In order to exclude diurnal changes of transcript levels, the values are given in \% of the corresponding water control after the indicated period of time.

these factors may specifically stabilize SUT1 mRNA or destabilize SUT2 and SUT4 mRNA.

In order to distinguish between transcriptional and posttranscriptional control, experiments with translational and transcriptional inhibitors have been performed simultaneously (Figs. 3B, 4). In the presence of both, transcriptional and translational inhibitors the half life of StSUT1 mRNA decreased compared to the untreated control (Fig. 3B) as already observed using both inhibitors alone. 

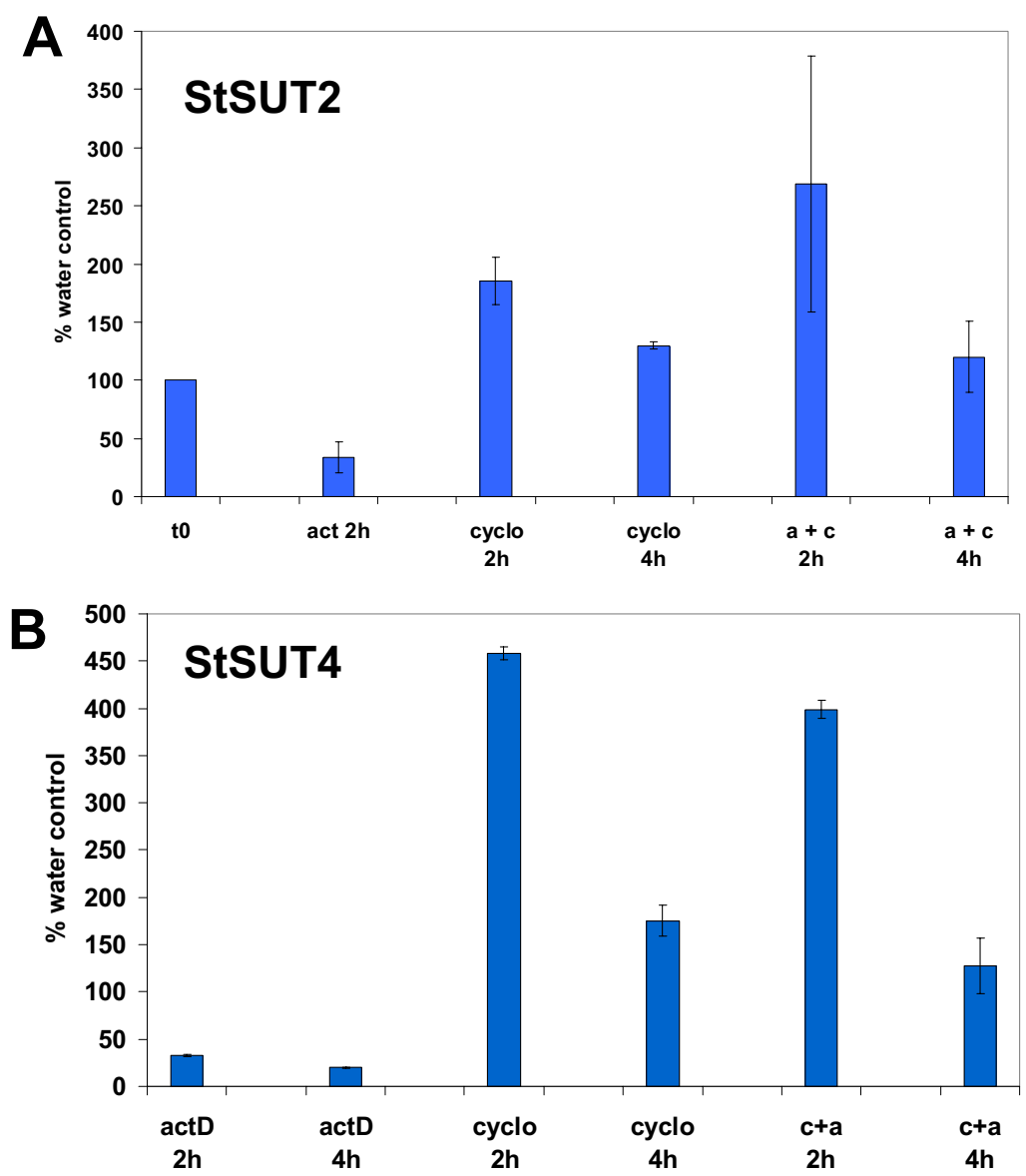

Fig. (4). Real time PCR analysis of sucrose transporter SUT2 and SUT4 mRNA stability in the presence of transcriptional and translational inhibitors. A. StSUT2 mRNA quantification in the presence of actinomycin D (actD), CHX (cyclo) and both inhibitors (c+a). Half life of StSUT2 mRNA was calculated based on real time quantification and presented in table 1. StSUT2 mRNA accumulates upon 4 h CHX treatment. StSUT2 mRNA half life is prolonged by CHX even if transcription is blocked (c+a) B. StSUT4 mRNA half life was calculated by actinomycin D treatment and presented in table 1. Inhibition of translation increases StSUT4 transcript accumulation 4.5 fold within 2 h. StSUT4 mRNA half life is prolonged by simultaneous treatment with translational and transcriptional inhibition (c+a).

In contrast, the half life of StSUT2 and StSUT4 mRNA was significantly prolonged in the presence of both inhibitors in comparison to the treatment with only the transcriptional inhibitor actinomycin D and the amount of StSUT2 and StSUT4 transcripts increased compared to the untreated control (Fig. 4). Thus, transcript half life is prolonged by CHX even when transcription is blocked.

For further confirmation of the StSUT1 regulation at the transcriptional level, transgenic plants overexpressing the cmyc tagged SoSUT1 gene under the constitutive 35Spromotor have been analyzed [15]. Plants overexpressing SoSUT1 under control of the constitutive $35 \mathrm{~S}$ promoter do not follow the diurnal regulation of the mRNA (Supplement 1). Analysis of the $35 \mathrm{~S}::$ SoSUT1 overexpressing potato plants showed furthermore, that the transcripts of the overexpressed c-myc tagged SUT1 gene is not destabilized in the presence of cylcoheximide as previously shown for SUT1 expressed under the endogenous promoter (see above) arguing for transcriptional control of SUT1 mRNA and requirement of cis-acting promoter elements for its diurnal SUT1 regulation (Supplement 1). Diurnal mRNA oscillation due to post-transcriptional mRNA decay is thus unlikely in case of SUT1.

\section{Auxin Induces StSUT1 Expression}

Real time analysis of potato leaves pre-incubated with 2,4-D for 2 to $4 \mathrm{~h}$ revealed a strong increase of StSUT1 mRNA amount (Fig. 5A). Not only mRNA accumulation is observed, but also the StSUT1 protein content follows the increasing SUT1 mRNA accumulation transiently upon treatment with $5 \mu \mathrm{M} 2,4-\mathrm{D}$ and progressively upon treatment with $5 \mu \mathrm{M}$ BAP (Fig. 5B). The inducibility of StSUT1 by phytohormones such as auxin or cytokinin at the transcriptional level was previously shown [24].

If auxin is supplied and simultaneously, the translation is blocked by CHX as shown in Fig. 5A, no StSUT1 transcript accumulation can be observed (Fig. 5A). It is concluded, that auxin induction of StSUT1 requires de novo protein synthesis since the effect is completely abolished in the presence of CHX. Therefore, the analyzed sucrose transporter StSUT1 belongs to the so-called late auxin responsive genes.

In contrast to StSUT1, StSUT4 is only marginally induced by auxin, and transcript accumulation is strongly increased upon CHX application (Fig. 5C). Similar observations have been done with StSUT2 transcript levels (data not shown). Simultaneous application of 2,4-D and CHX results in low transcript amounts (Fig. 5C). 

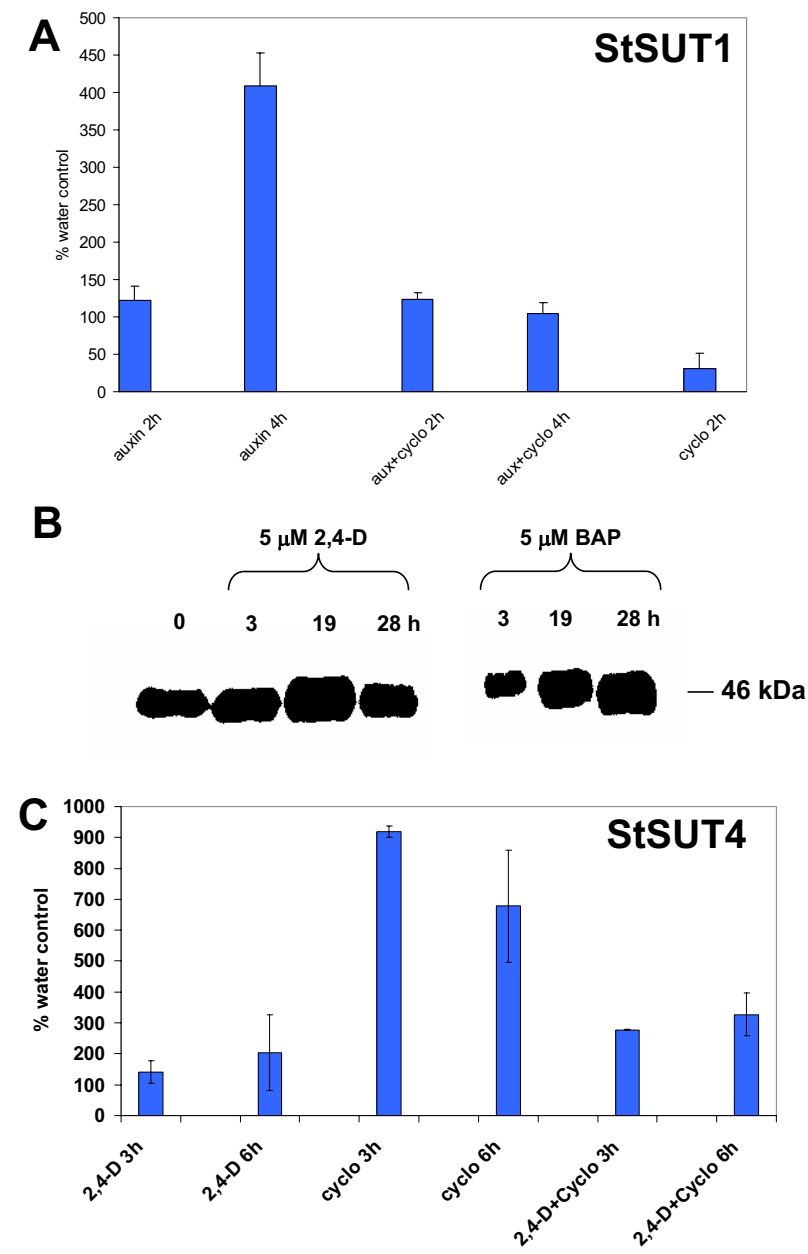

Fig. (5). Expression of the sucrose transporter StSUT1 is induced by auxin $(5 \mu \mathrm{M} 2,4-\mathrm{D})$ both at the mRNA and the protein level. A. Real time-PCR quantification of StSUT1 upon 2 and $4 \mathrm{~h}$ treatment with $5 \mu \mathrm{M} 2,4-\mathrm{D}$ and in the presence of $5 \mu \mathrm{M} 2,4-\mathrm{D}$ and $10 \mu \mathrm{M}$ $\mathrm{CHX}$ or $10 \mu \mathrm{M}$ CHX alone. Auxin induction of StSUT1 transcript accumulation is abolished by CHX. B. Western Blot Analysis with microsomal membranes separated by SDS-PAGE and immunodetected with StSUT1-specific antibodies. Potato leaves were treated with either $5 \mu \mathrm{M} 2,4-\mathrm{D}$ or $5 \mu \mathrm{M}$ BAP and $15 \mu \mathrm{g}$ of total membrane proteins were loaded per lane. StSUT1 protein amount increases upon cytokinin treatment (BAP) and transiently upon auxin treatment. C. Real time quantification of StSUT4 transcripts upon the same treatment shown in A. StSUT4 mRNA increases only marginally upon auxin treatment. Cycloheximide treatment increases StSUT4 mRNA half life significantly. The stabilizing effect by CHX is completely abolished in the presence of auxin $(2,4-\mathrm{D}+$ cyclo).

It is known, that $A U X / I A A$ genes belong to the early auxin responsive genes and encode in most cases very short lived repressors of transcription. Repression is achieved by forming ARF heterodimers preventing ARF activation by binding to the AuxRE cis-element. AUX/IAA proteins are degraded by the ubiquitin-mediated $26 \mathrm{~S}$ proteasome pathway.

In order to test whether SUT transcription depends on short-lived proteins which are degraded via the $26 \mathrm{~S}$ protea- some pathway, transcript quantification was performed in the presence of the inhibitor of the $26 \mathrm{~S}$ proteasome, MG132 [30].

The inhibitor of the 26S proteasome MG132 does not affect transcript stability or accumulation, whereas CHX leads to a decreased StSUT1 transcript amount (Fig. 6A).

Simultaneous treatment with CHX and MG132 lead to low StSUT1 transcript amounts as with CHX alone. Therefore the inhibitor of the $26 \mathrm{~S}$ proteasome is not able to stabilize StSUT1 mRNA in the presence of CHX. It is concluded that proteins responsible for high $S t S U T 1$ transcript levels under normal conditions (in the absence of $\mathrm{CHX}$ ) are not degraded by the $26 \mathrm{~S}$ proteasome since StSUT1 transcripts disappear efficiently within $4 \mathrm{~h}$ of incubation with both inhibitors.

CHX has the opposite effect on SUT2 and SUT4 transcript accumulation, which increase within only $2 \mathrm{~h}$ of treatment (Figs. 4A, 4B, 5C, 6B). MG132 has no significant effect on StSUT2 transcript amounts (Fig. 6B). But the inhibitor of the $26 \mathrm{~S}$ proteasome, MG132, is able to prevent the stabilising CHX effect on StSUT2 transcripts leading to similar transcript amounts as seen in the untreated control (Fig. 6B). Therefore, negative effectors on StSUT2 transcript accumulation are most likely degraded via the ubiquitinmediated $26 \mathrm{~S}$ proteasome pathway since inhibition of their degradation abolished the effect of the inhibition of their synthesis.

\section{CONCLUSIONS}

\section{Phloem Mobility of SUT1 mRNA}

From several independent studies the presence of SUT1 mRNA in the phloem sap of several species was known $[11,12,13]$ and the StSUT1 mRNA was localized electron microscopically in the companion cells as well as in the sieve elements of the phloem in potato plants [9]. For many of the known mRNAs present in the phloem sap, the phloem mobility has been analyzed via interspecific graft experiments [12]. The mobility of the sucrose transporter mRNA has not yet been analyzed. We were able to show phloem mobility of StSUT1, NtSUT1, LeSUT1-GUS and SoSUT1myc transcripts either between parasite and host plants or between grafted plants. Thereby, we confirmed previous investigations regarding the phloem mobility of sucrose transporter mRNA from Cucurbita maxima from the host into the dodder plant Cuscuta pentagona Engelm [31].

The detailed analysis of the mobility of pumpkin and tomato phloem transcripts from the host plants into the dodder plant Cusucta pentagona by microarray and RT-PCR analysis revealed species-specific differences. Only three out of the eight mentioned phloem mobile pumpkin transcripts, were detectable in the parasite, namely, CmNACP, CmRKYP and CmSUT1P [31]. This argues for the specificity of the mRNA transport through symplasmic connections between host plant and parasite, since the ability to be translocated into the dodder plants is not related to the transcript amount in the host plant [31]. It is discussed whether the mobility of specific mRNAs allows interspecific communication and whether Cuscuta can recognize, use, and respond to specific plant mRNAs. 

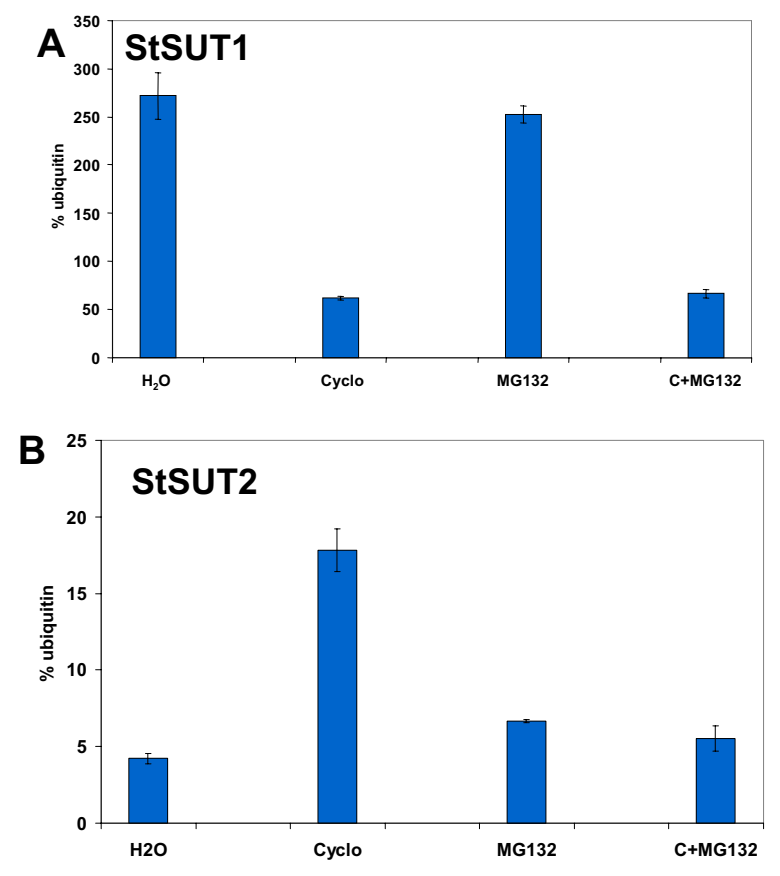

Fig. (6). Effects of the 26S proteasome inhibitor MG132 on sucrose transporter mRNA half life. A. 4 h CHX treatment affects StSUT1 transcript stability. This effect is not decreased in the presence of the 26S proteasome inhibitor MG132. B. StSUT2 mRNA half life increase upon $2 \mathrm{~h}$ of $\mathrm{CHX}$ treatment. This stabilizing effect is abolished by the $26 \mathrm{~S}$ proteasome inhibitor MG132. Note that relative quantification is not related to the corresponding water control as in Fig. (3-5) but to the amount of ubiquitin transcripts after $4 \mathrm{~h}$ of incubation (A, StSUT1) and $2 \mathrm{~h}$ of incubation (B, StSUT2).

Tomato microarray analysis revealed as much as 474 different tomato transcripts identified in the parasite and most of these mRNA play a role in mediating plant response to the environment [31].

Also heterograft experiments argue for specificity of the mRNA delivery into the shoot apices of grafted plants, since only three out of eight phloem-specific mRNAs were detected in graft scions [12]. It was shown that the RNA entry into the shoot apex is a selective process [32].

Thus phloem-mobility of mRNAs is seemingly not a general feature of phloem-specific RNAs and SUT1 mRNA is one of the specific phloem mobile components in grafted plants as well as between host and parasitic plants.

The ability of StSUT1 mRNA to move through plasmodesmata has previously been shown in microinjection experiments [10]. Co-injection of StSUT1 mRNA together with the RNA-binding phloem protein CmPP16 significantly increased the efficiency of plasmodesmal transport. In 10 out of 10 experiments co-injected fluorescently labelled StSUT1 mRNA was able to move from the microinjected into neighbouring cells when co-injected with CmPP16. The phloem mobility of both the CmPP16 mRNA and protein was shown by heterograft experiments [12]. For many other phloemspecific genes, mobility of only their mRNA, but not of the corresponding protein was observed. This is the case for CmNACP, CmWRKYP, CmRINGP, CmGAIP, CmRABP,
CmSTP etc. In all cases, a regulatory role of these phloemmobile mRNAs has been postulated [12].

In contrast, phloem mobility of the two structural phloem proteins PP1 and PP2 are detectable in the graft partner in heterografts, whereas their mRNA is obviously not phloem mobile [33]. This argues again for the selectivity of phloem transported mRNAs.

\section{Transcriptional control of SUT1, post-transcriptional control of SUT2 and SUT4}

We showed that the half life of solanaceous sucrose transporter mRNAs ranges between 60 and $130 \mathrm{~min}$. (this work). The half life of the $B v S U T 1$ mRNA was determined to be $108 \mathrm{~min}$ and repression by sucrose takes place at the transcriptional level as shown by nuclear run off analysis [29].

Thus, sucrose transporter mRNAs are very short lived and accumulation is tightly controlled at various levels. Whereas, transcriptional control of the diurnally expressed StSUT1 gene seems to have high impact on its accumulation, StSUT2 and StSUT4 transcript accumulation is highly dependent on the de novo biosynthesis of negative acting regulators indicated by the enhanced stability in the presence of CHX within only $2 \mathrm{~h}$. Prolongation of mRNA half life by inhibition of transcription and translation argues for a tight post-transcriptional control of these two sucrose transporterrelated genes in a sequence-specific manner.

It was shown previously, that the LeSUT1 mRNA follows a diurnal expression pattern [9]. In contrast to carrot, where DcSUT1 and DcSUT2 are diurnally regulated in leaves, but expressed at a constantly low level in tap roots [14], the diurnal rhythm of sucrose transporter expression in potato plants is also detectable in sink organs such as flowers (Chincinska, Kühn, unpublished). Sucrose transporter mRNA oscillation is not only detectable under dark/light cycles, but also under constant light conditions [25] arguing for circadian regulation.

For several circadian genes, a specific post-transcriptional mRNA decay mechanism has been postulated [34]. The circadian control of messenger stability was found to be associated to a sequence specific decay pathway $[34,35]$. Instability determinants of clock controlled mRNAs might be located within untranslated regions, introns or within the coding region as shown for mRNA of CIRCADIAN CLOCK ASSOCIATED 1 (CCA1) [36]. Here we show that both, the StSUT2 and the StSUT4 mRNA undergo sequence-specific post-transcriptional mRNA decay as previously shown for other circadian genes [34]. The half life of the two transcripts is increased by $\mathrm{CHX}$ even in the presence of transcriptional inhibitor actinomycin D (Figs. 4A, 4B).

RNA stability is triggered by elements like the well characterized AUUUA motif, which is known to accelerate mRNA decay of many eukaryotic transcripts [37]. StSUT2 mRNA contains one of these motifs in the 3'UTR, the StSUT1 mRNA contains one and the StSUT4 mRNA two AUUUA motifs within the coding region (Supplement 2).

In a project where two million small RNAs from Arabidopsis seedlings and inflorescences were sequenced, new micro RNAs were identified [10]. Among the set of 75.000 non-redundant sequences most of the small RNAs were 


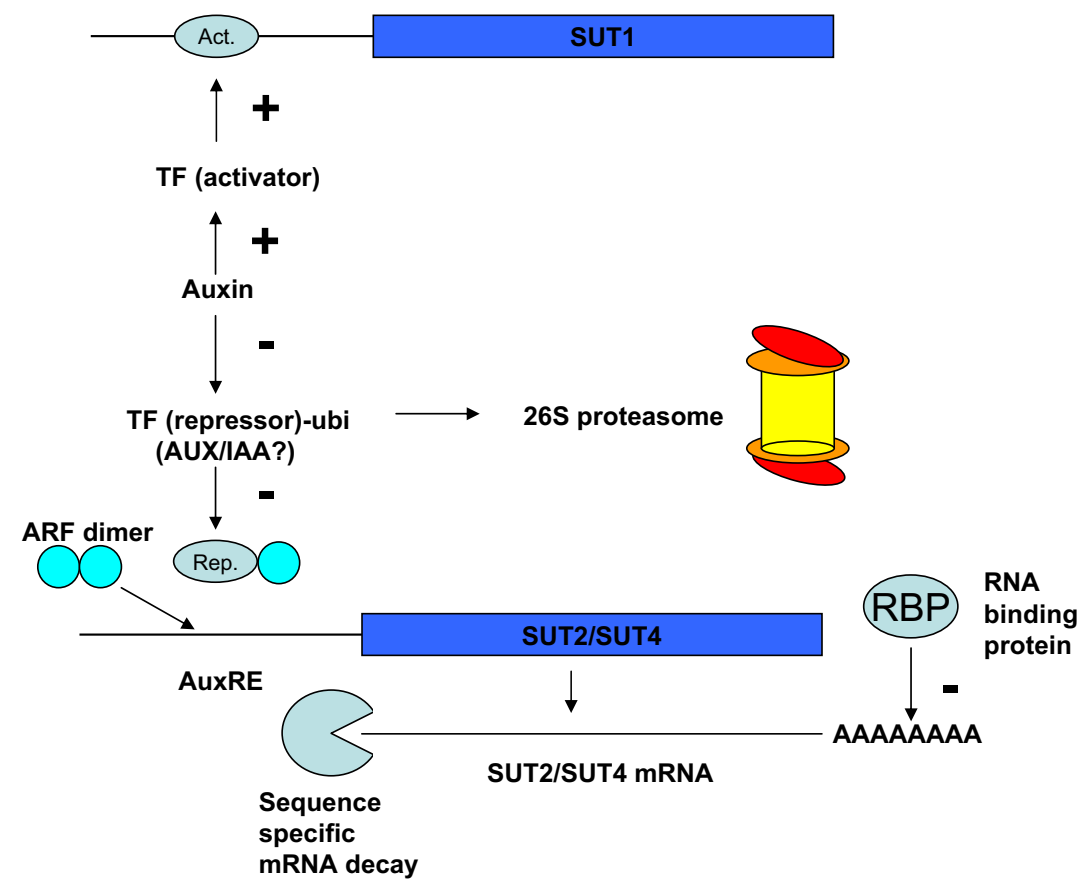

Fig. (7). Hypothetical model for the transcriptional control via auxin and post-transcriptional mRNA decay of SUT2 and SUT4 by short-lived mRNA-binding proteins which are degraded via the 26S proteasome pathway. TF: transcription factor; Ubi: ubiquitin; ARF: auxin response factor; AuxRE : auxin responsive element, RBP: RNA binding protein.

miRNAs and more than half represented low abundant small interfering RNAs (siRNAs) matching genes or intergenic regions. Micro RNAs matching sucrose transporter genes were found for all known sucrose transporter genes from Arabidopsis except for AtSUT2 and AtSUT4 (according to the supplementary files of [38]), the orthologous genes of StSUT2 and StSUT4. Thus, the control of SUT2 and SUT4 genes via micro RNAs is unlikely and it is assumed that very short lived RNA-binding proteins play an important role in the regulation of the $S U T 2$ and SUT4 expression level.

\section{Auxin Regulation of Sucrose Transporters}

Auxin induced genes fall into two classes: early auxin genes are primary response genes which are insensitive to protein synthesis inhibitors such as CHX. Some of these early genes encode proteins that regulate the transcription of secondary or late response genes that require de novo protein synthesis, their expression can be blocked by CHX. A conserved auxin response element (AuxRE) can be found in the promoter region of LeSUT2. It represents the binding site of the auxin response factor ARF, a transcriptional activator, which is regulated by short-lived Aux/IAA proteins acting as repressor of ARF [39].

Aux/IAA proteins are known to have a half life of only few minutes and to be degraded via the proteasome pathway. This degradation is promoted by auxin. A negative feedback mechanism induces $A U X / I A A$ transcription to ensure a short term auxin effect.

A transcriptional activator seems to be required for StSUT1 induction which is auxin-dependent and short-lived, but not degraded via the ubiquitin-mediated proteasome pathway, since the inhibitor of the $26 \mathrm{~S}$ proteasome did not lead to transcript stabilisation in the presence of CHX (Fig. 6A). In case of SUT2/SUT4 the mRNA stabilizing effect of
CHX is prevented by MG132 arguing for a ubiquitinmediated degradation of the short-lived inhibitor of SUT2 and SUT4 transcript accumulation via the $26 \mathrm{~S}$ proteasome (Fig. 6B).

The change of SUT1 transcript levels upon CHX occurs within $4 \mathrm{~h}$ upon $\mathrm{CHX}$ treatment, whereas the increase of SUT2 and SUT4 mRNA is immediately detectable within only $2 \mathrm{~h}$ after CHX treatment (Figs. 3, 4, 5 and 6). The nonredundancy of SUT2 and SUT4 sucrose transporters, the low and ubiquitous expression level in the phloem, together with the low codon bias and the tight short term regulation of their expression pattern makes these genes potential candidates for regulatory processes. Auxin-dependent regulation of the transcriptional efficiency of sucrose transporter genes together with regulation of the transcript stability by a sequence specific mRNA decay mechanism might represent a possibility to coordinate the interplay of sucrose transporters of higher plants as suggested in the hypothetical model of Fig. (7).

The model in Fig. (7) summarises the positive effect of auxin on the transcriptional activity of the $S U T 1$ genes via transcriptional activators, whereas SUT2 and SUT4 genes are obviously negatively affected by short-lived proteins either at the transcriptional level potentially via AUX/IAA proteins or at the post-transcriptional level via RNA-binding proteins. The fact that SUT2 and SUT4 mRNA half life is indeed affected at the post-transcriptional level (as shown in Fig. 4) points on the important regulatory function of phloemspecific RNA-binding proteins and sequence-specific mRNA degradation.

In summary, StSUT1, NtSUT1 as well as SoSUT1-c-myc mRNA and LeSUT1-GUS mRNA are phloem mobile although they are very short-lived with a half life between 1 
and $2 \mathrm{~h}$. StSUT1 regulation required cis-acting promoter elements to show diurnal oscillation as well as decreased transcript amounts in the presence of the translational inhibitor CHX. In contrast, SUT2 and SUT4 from potato and tomato are regulated at the post-transcriptional level.

Thus, mRNA binding proteins are necessary to enhance mRNA stability during mRNA transport through the phloem. Sequence-specific RNA binding proteins might play a role in the selective stability of phloem mobile transcripts since it was shown, that not all of the transcripts present in the phloem sap are able to move within grafted plants or between host and parasitic plants [31].

As we found RNA-binding protein-dependent stability of SUT mRNA, we began to screen for mRNA-binding proteins using a yeast three hybrid system and sucrose transporter mRNAs as bait. These proteins might be involved in either stabilisation of the SUT1 mRNA during long distance transport in the phloem in form of ribonucleoprotein particles (RNPs) or might represent RNA-binding proteins able to affect the stability of SUT2 or SUT4 transcripts. These proteins could also contribute to the circadian control of the latter sucrose transporter mRNAs.

\section{ACKNOWLEDGEMENTS}

This work was supported by grants from the DFG to C.K. and A.H. (SFB 429) and to H.H. (SPP1108). We gratefully acknowledge Angelika Pötter for the care of greenhouse plants.

\section{ABBREVIATIONS}

$\begin{array}{lll}\mathrm{ARF} & = & \text { auxin response factor } \\ \mathrm{SUT} & = & \text { sucrose transporter } \\ \mathrm{GA} & = & \text { gibberellic acid } \\ \mathrm{ABA} & = & \text { abscisic acid } \\ \mathrm{actD} & = & \text { actinomycin } D \\ \mathrm{CHX} & = & \text { cycloheximide } \\ \mathrm{TEF} & = & \text { transcription elongation factor } \\ \text { GUS } & = & \text { B-Glucuronidase } \\ \text { RT-PCR } & = & \begin{array}{l}\text { reverse transcription polymerase chain } \\ \text { reaction }\end{array}\end{array}$

\section{REFERENCES}

[1] Riesmeier JW, Hirner B Frommer WB. Potato sucrose transporter expression in minor veins indicates a role in phloem loading. Plant Cell 1993; 5: 1591-8.

[2] Barker L, Kuhn C, Weise A, et al. SUT2, a putative sucrose sensor in sieve elements. Plant Cell 2000; 12: 1153-64.

[3] Weise A, Barker L, Kühn C, et al. A new subfamily of sucrose transporters, SUT4, with low affinity/high capacity localized in enucleate sieve elements of plants. Plant Cell 2000; 12: 1345-55.

[4] Riesmeier JW, Willmitzer L, Frommer WB. Evidence for an essential role of the sucrose transporter in phloem loading and assimilate partitioning. EMBO J 1994; 13: 1-7.

[5] Kühn C, Quick WP, Schulz A, Riesmeier J, Sonnewald U, Frommer WB. Companion cell-specific inhibition of the potato sucrose transporter SUT1. Plant Cell Environ 1996; 19: 1115-23.

[6] Hackel A, Schauer N, Carrari F, Fernie AR, Grimm B, Kühn C. Sucrose transporter LeSUT1 and LeSUT2 inhibition affects tomato fruit development in different ways. Plant J 2006; 45: 180-92.
[7] Reinders A, Schulze W, Kühn C, et al. Protein-protein interactions between sucrose transporters of different affinities colocalized in the same enucleate sieve element. Plant Cell 2002; 14: 1567-77.

[8] Kühn C. Comparison of the sucrose transporter systems of different plant species. Plant Biol 2003; 5: 215-32.

[9] Kühn C, Franceschi VR, Schulz A, Lemoine R, Frommer WB. Macromolecular trafficking indicated by localization and turnover of sucrose transporters in enucleate sieve elements. Science 1997; 275: 1298-300.

[10] Xoconostle-Cázares B, Xiang Y, Ruiz-Medrano R, et al. Plant paralog to viral movement protein that potentiates transport of mRNA into the phloem. Science 1999; 283: 94-8.

[11] Doering-Saad C, Newbury HJ, Bale JS, Pritchard J. Use of aphid stylectomy and RT-PCR for the detection of transporter mRNAs in sieve elements. J Exp Bot 2002; 53: 631-7.

[12] Ruiz-Medrano R, Xoconostle-Cazares B, Lucas WJ. Phloem longdistance transport of CmNACP mRNA: implications for supracellular regulation in plants. Development 1999; 126: 4405-19.

[13] Knop C, Voitsekhovskaja O, Lohaus G. Sucrose transporters in two members of the Scrophulariaceae with different types of transport sugar. Planta 2001; 213: 80-91.

[14] Shakya R, Sturm A. Characterization of source- and sink-specific sucrose/H+ symporters from carrot. Plant Physiol 1998; 118: 147380.

[15] Leggewie G, Kolbe A, Lemoine R, et al. Overexpression of the sucrose transporter SoSUT1 in potato results in alterations in leaf carbon partitioning and in tuber metabolism but has little impact on tuber morphology. Planta 2003; 217: 158-67.

[16] Weise A, Lalonde S, Kühn C, Frommer WB, Ward JM. Introns control expression of sucrose transporter LeSUT1 in trichomes, companion cells and in guard cells. Plant Mol Biol 2008; submitted.

[17] Lalonde S, Weise A, Walsh RP, Ward JM, Frommer WB. Fusion to GFP blocks intercellular trafficking of the sucrose transporter SUT1 leading to accumulation in companion cells. BMC Plant Biol 2003; 3: 8 .

[18] Murashige T, Skoog F. A revised medium for rapid growth and bioassays with tobacco tissue cultures. Physiol. Plant 1962; 15: 473-97.

[19] Martinez-Garcia JF, Virgos-Soler A, Prat S. Control of photoperiod-regulated tuberization in potato by the Arabidopsis floweringtime gene CONSTANS. Proc Natl Acad Sci USA 2002; 99: 152116.

[20] Martinez-Garcia JF, Garcia-Martinez JL, Bou J, Prat S. The Interaction of Gibberellins and Photoperiod in the Control of Potato Tuberization. J Plant Growth Regul 2001; 20: 377-86.

[21] Schneider A, Hausler RE, Kolukisaoglu U, et al. An Arabidopsis thaliana knock-out mutant of the chloroplast triose phosphate/phosphate translocator is severely compromised only when starch synthesis, but not starch mobilisation is abolished. Plant $\mathrm{J}$ 2002; 32: 685-99.

[22] Haupt S, Oparka KJ, Sauer N, Neumann S. Macromolecular trafficking between Nicotiana tabacum and the holoparasite Cuscuta reflexa. J Exp Bot 2001; 52: 173-7.

[23] Albert M, Werner M, Proksch P, Fry SC, Kaldenhoff R. The cell wall-modifying xyloglucan endotransglycosylase/hydrolase LeXTH1 is expressed during the defence reaction of tomato against the plant parasite Cuscuta reflexa. Plant Biol (Stuttg) 2004; 6: 4027.

[24] Harms K, Wohner RV, Schulz B, Frommer WB. Isolation and characterization of P-type $\mathrm{H}(+)$-ATPase genes from potato. Plant Mol Biol 1994; 26: 979-88.

[25] Chincinska I, Liesche J, Krügel U, et al. The sucrose transporter StSUT4 from Solanum tuberosum affects flowering, tuberization and shade avoidance response. Plant Physiol 2008; 146: 515-28.

[26] Harmer SL, Kay SA. Positive and negative factors confer phasespecific circadian regulation of transcription in Arabidopsis. Plant Cell 2005; 17: 1926-40.

[27] Meyer S, Lauterbach C, Niedermeier M, Barth I, Sjolund RD, Sauer N. Wounding enhances expression of AtSUC3, a sucrose transporter from Arabidopsis sieve elements and sink tissues. Plant Physiol 2004; 134: 684-93.

[28] Lam LT, Pickeral OK, Peng AC, et al. Genomic-scale measurement of mRNA turnover and the mechanisms of action of the anticancer drug flavopiridol. Genome Biol 2001; 2: RESEARCH0041. 
[29] Vaughn MW, Harrington GN, Bush DR. Sucrose-mediated transcriptional regulation of sucrose symporter activity in the phloem. Proc Natl Acad Sci USA 2002; 99: 10876-80.

[30] Lee DH, Goldberg AL. Selective inhibitors of the proteasomedependent and vacuolar pathways of protein degradation in Saccharomyces cerevisiae. J Biol Chem 1996; 271: 27280-4.

[31] Roney JK, Khatibi PA, Westwood JH. Cross-species translocation of mRNA from host plants into the parasitic plant dodder. Plant Physiol 2007; 143: 1037-43.

[32] Foster TM, Lough TJ, Emerson SJ, et al. A surveillance system regulates selective entry of RNA into the shoot apex. Plant Cell 2002; 14: 1497-508.

[33] Golecki B, Schulz A, Thompson GA. Translocation of structural P proteins in the phloem. Plant Cell 1999; 11: 127-40.

[34] Lidder P, Gutierrez RA, Salome PA, McClung CR, Green PJ. Circadian control of messenger RNA stability. Association with a sequence-specific messenger RNA decay pathway. Plant Physiol 2005; 138: 2374-85.
[35] Lidder P, Johnson MA, Sullivan ML, et al. Genetics of the DSTmediated mRNA decay pathway using a transgene-based selection. Biochem Soc Trans 2004; 32: 575-7.

[36] Yakir E, Hilman D, Hassidim M, Green RM. CCA1 transcript stability and the entrainment of the circadian clock in Arabidopsis. Plant Physiol 2007; 145: 925-32.

[37] Chen CY, Shyu AB. AU-rich elements: characterization and importance in mRNA degradation. Trends Biochem Sci 1995; 20: 46570 .

[38] Lu C, Tej SS, Luo S, Haudenschild CD, Meyers BC, Green PJ. Elucidation of the small RNA component of the transcriptome. Science 2005 ; 309: 1567-9.

[39] Ulmasov T, Hagen G, Guilfoyle TJ. Activation and repression of transcription by auxin-response factors. Proc Natl Acad Sci USA 1999; 96: 5844-9.

[40] Tóth K, Wang Q, Sjolund R. Monoclonal antihodies against phloem P-protein from plant tissue cultures. I. Microscopy and biochemical analysis. Am J Bot 1994; 81: 1370-7.

(C) He et al.; Licensee Bentham Open.

This is an open access article distributed under the terms of the Creative Commons Attribution License (http://creativecommons.org/license/by/2.5/), which permits unrestrictive use, distribution, and reproduction in any medium, provided the original work is properly cited. 


\section{Supplement 1}

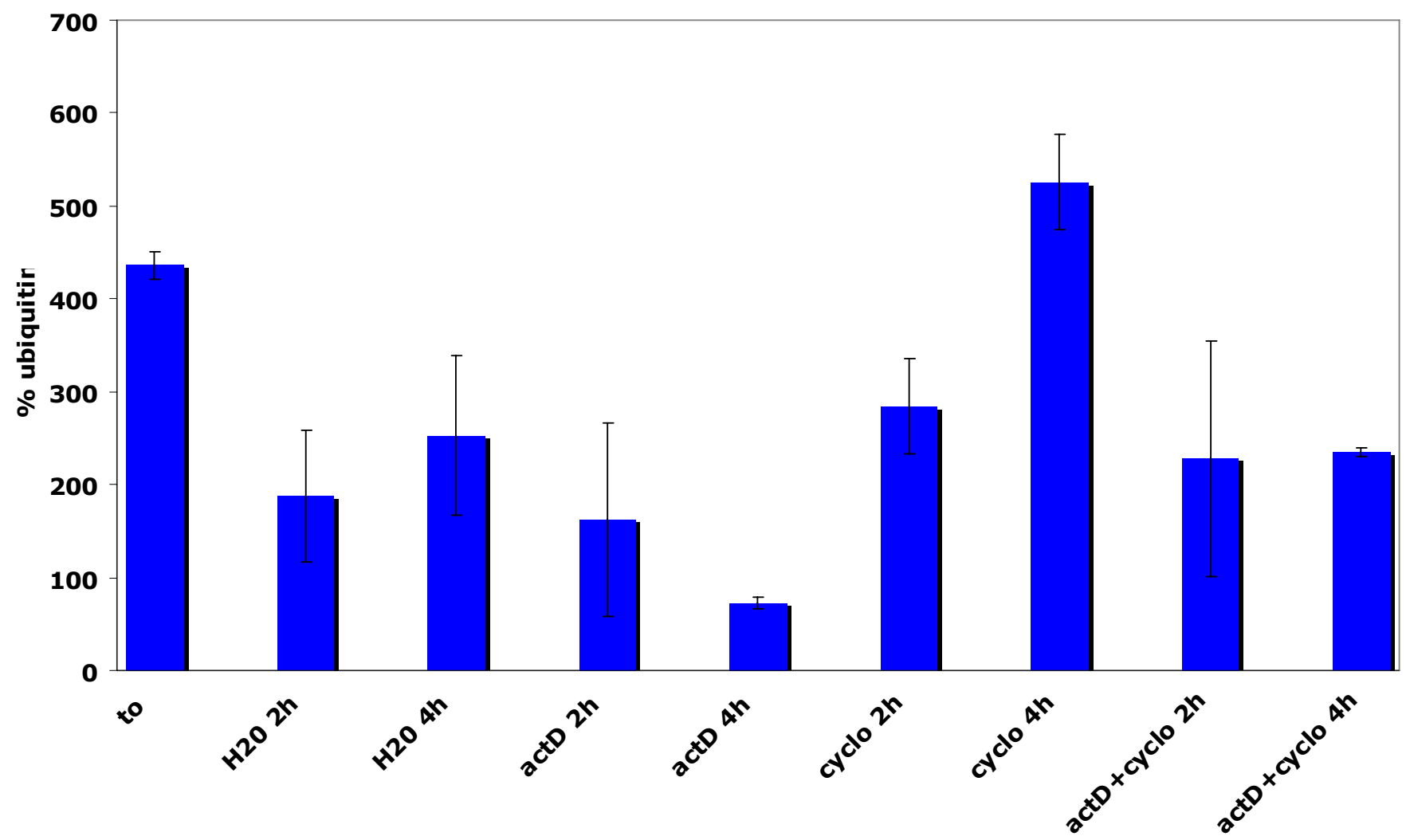

Real time PCR analysis of SoSUT1-myc expression in transgenic potato plants, where SoSUT1 expression is under control of the $35 \mathrm{~S}$ promoter. SoSUT1 expression does not follow a diurnal expression pattern as it is shown for the endogenous StSUT1 gene. Inhibition of translation by cycloheximide has no destabilizing effect in SoSUT1 transcripts as shown for the endogenous StSUT1 gene. 


\section{Supplement 2}

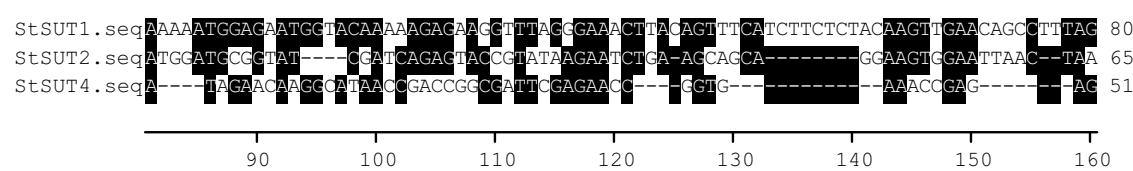

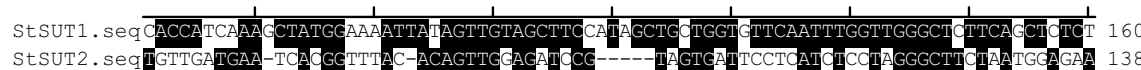

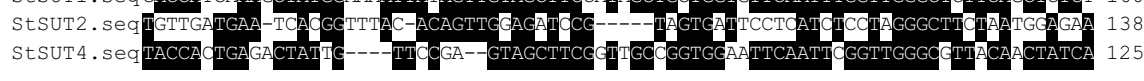

$\begin{array}{llllllll}1 & 1 & 1 & 1 & 1 & 1 & 1 & 1 \\ 170 & 180 & 190 & 200 & 210 & 220 & 230 & 240\end{array}$

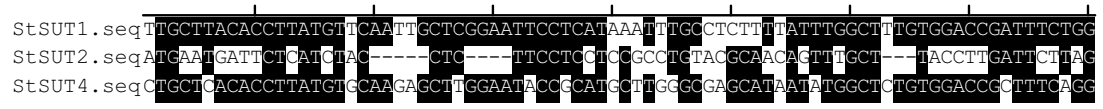

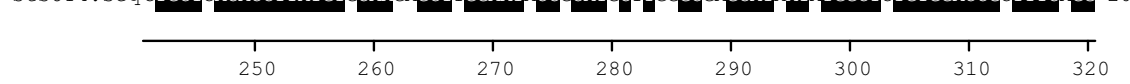

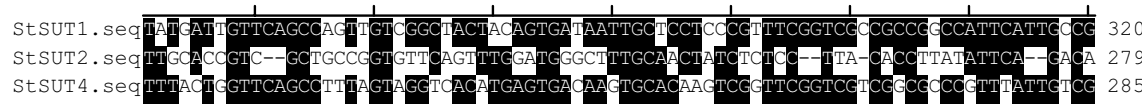

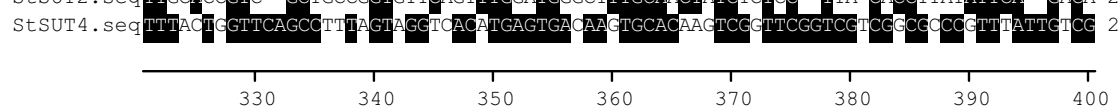

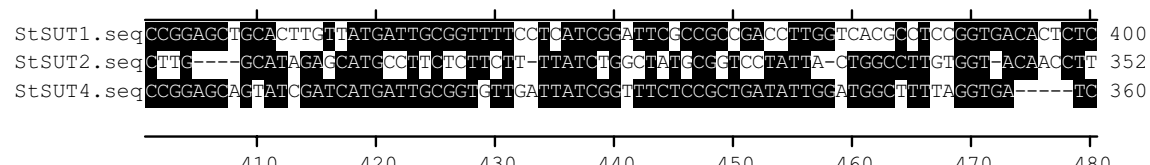

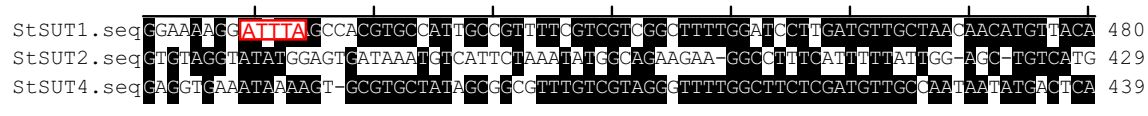

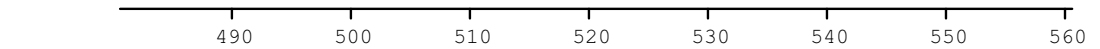

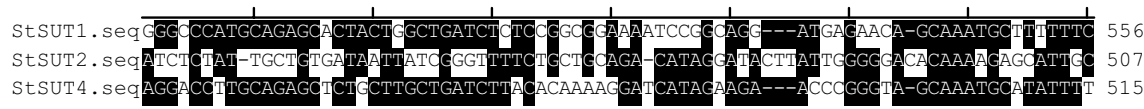

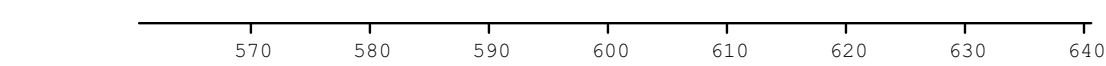

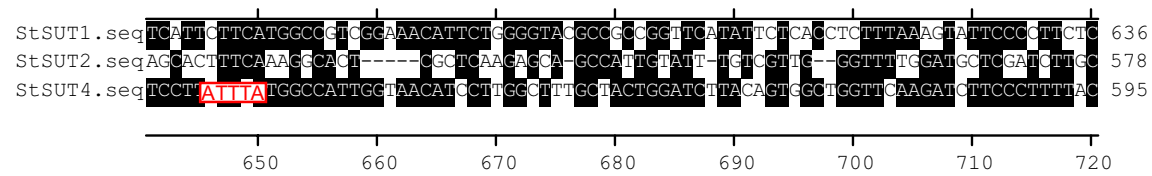

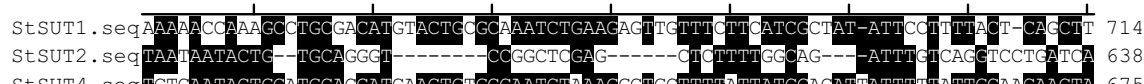

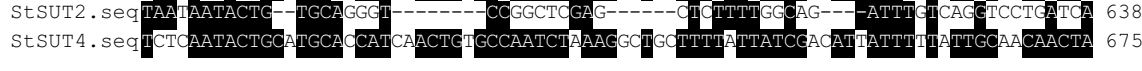

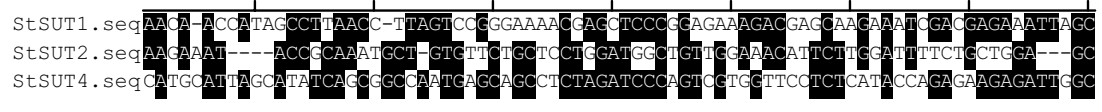

$\frac{1}{\frac{1}{1}} \frac{1}{1} \frac{1}{1} \frac{1}{1} \frac{1}{1} \frac{1}{1} \frac{1}{1} \frac{1}{1}$

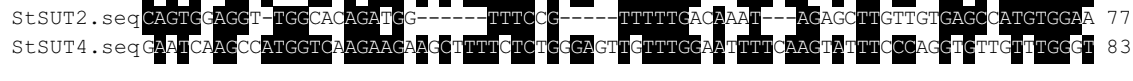

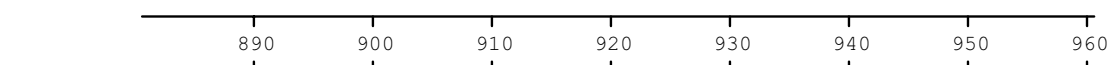

sern san

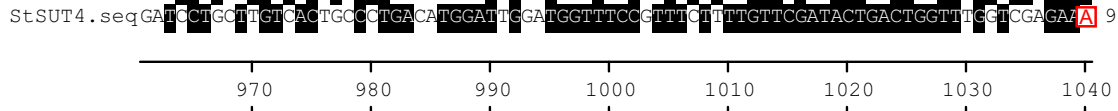

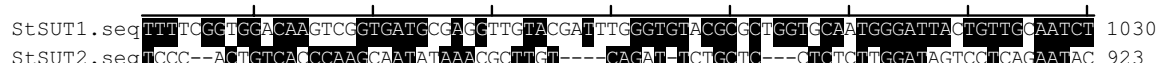
stam 


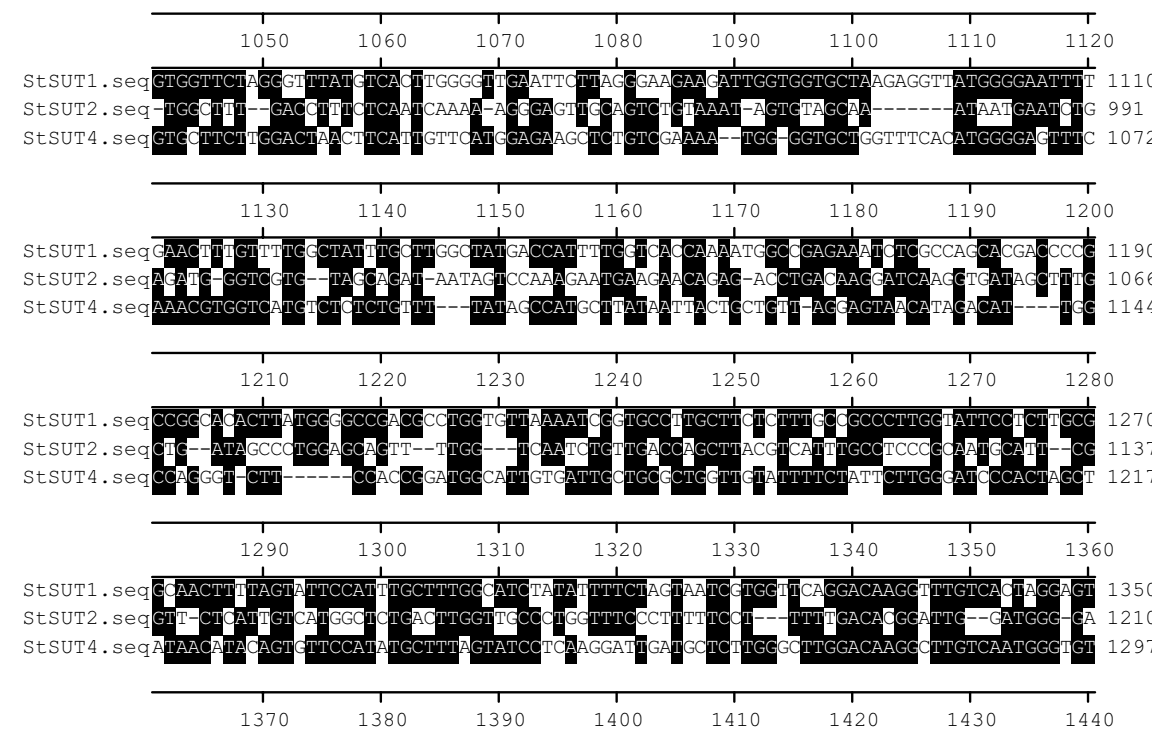

a 는

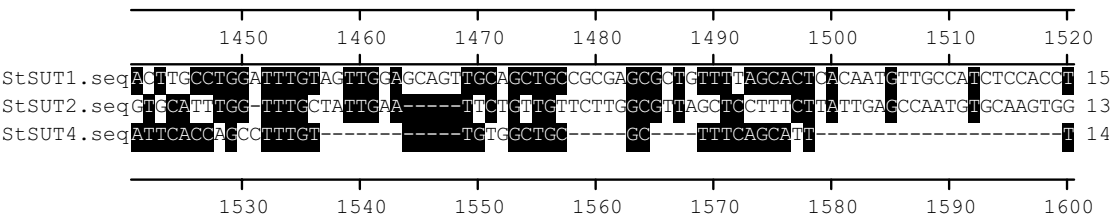

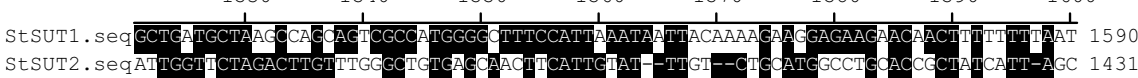
a dim \begin{tabular}{llllllll}
\hline 1610 & 1620 & 1630 & 1640 & 1650 & 1660 & 1670 & 1680
\end{tabular}

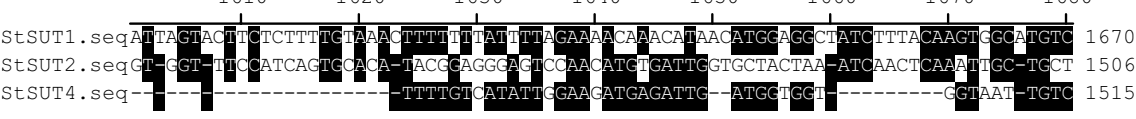

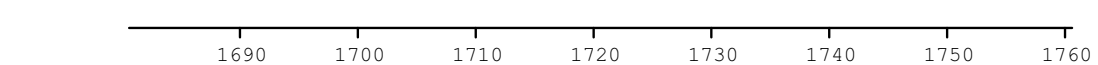

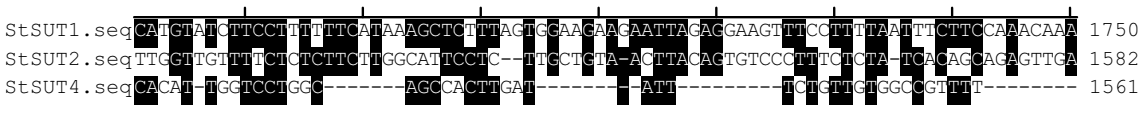

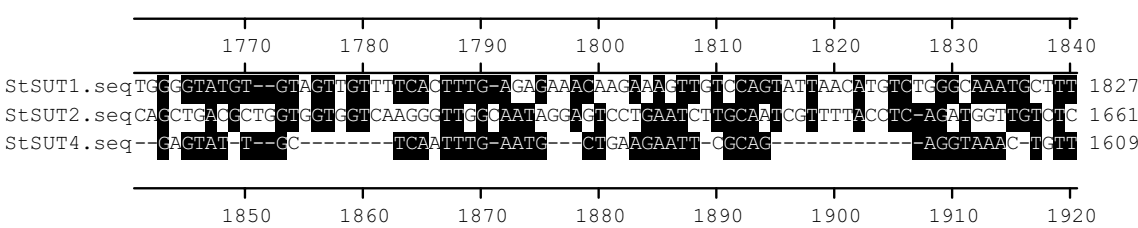

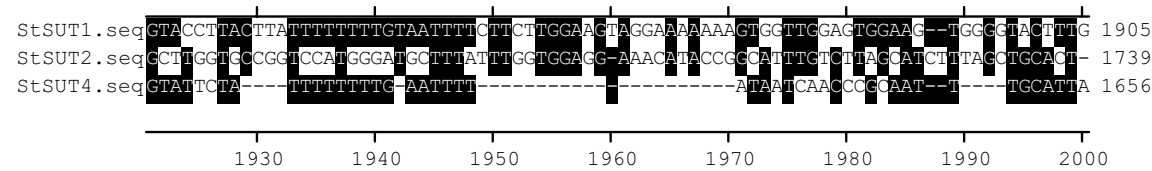

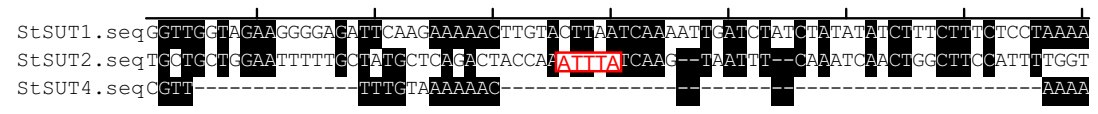
StSUT1. seq $\overline{A A D A}$
StSUT2. seqTGA
StSUT 4 . seq AAA 